\author{
Marcin Sanakiewicz \\ Uniwersytet Marii Curie-Skłodowskiej w Lublinie
}

\title{
Telewizja performatywna'
}

\begin{abstract}
Streszczenie
W niniejszym artykule autor podejmuje próbę interpretacji telewizji jako zjawiska społeczno-kulturowego, osadzoną w studiach performatycznych. Podstawowe problemy dotyczą tego, ile rzeczywistości jest $\mathrm{w}$ telewizji oraz jak telewizja stwarza ułasną realność. Wnioski płynące z takiego ujęcia tematu określają badany fenomen jako system autopojetyczny, uwikłany w ciągłe graniczne relacje z prezentowanym przez siebie światem.
\end{abstract}

Słowa kluczowe: telewizja, real $T V$, performans, performatyka.

\section{Performative Television}

\begin{abstract}
This article is an attempt to interpret television as a social and cultural phenomenon, placed on performance studies. The main research questions concern the reality and its presence in television, and how television creates its own realism. This category of analysis provides the conclusion, that the subject of research is an autopoietic system involved with televised reality, throughout continual and simultaneously liminal relations.
\end{abstract}

Key words: television, real TV, performance, performance studies.

\section{Wprowadzenie}

Nowe krytyczne medioznawstwo pouinno uwzględniać w jak największym stopniu zróżnicowane oddziaływania społeczne i kulturowe, przekształcając «telewizyjne studiowanie» u praudziue «studia nad telewizją» ${ }^{2}$.

Telewizji od lat wieszczy się schyłek, upadek, zmierzch. Próbuje się kreślić wizje początku jej końca, niekiedy używając metafory „nowego początku” lub też upatrując koniecznych przekształceń w zderzeniu z nowymi mediami i cyberkulturą. Trzeba przyznać, że nie jest to do końca nieuprawnione, upisuje się przecież zarówno u polemiczny nurt medioznawczy, jak i krytyczną teorię społeczną. A jednak teleuizja od lat

1 Tekst jest autorskim uyborem fragmentóu książki poustałej na podstawie zuycięskiej pracy w pierwszej edycji konkursu Medi@stery, M. Sanakiewicz, Telewizja ponowoczesna. Logiki i imaginacje medialne, Novae Res, Gdynia 2016.

2 T. Miller, Turn Off TV Studies!, „Cinema Journal” 2005, vol. 45, nr 1, s. 100. 
utrzymuje pozycję medialnego hegemona, co wynika nawet z pobieżnych obserwacji rynku reklamy czy analiz sondaży dotyczących odbioru i korzystania z medium nie tylko przez starsze, ale także młodsze pokolenia.

Nie zmienia to wciąż faktu, że uspółcześnie telewizja stara się dopasowywać do zmian, jakie niosą ze sobą cyfryzacja, nowe technologie, sieć czy wreszcie przekształcenia tradycyjnego podziału na nadawców i odbiorców. W świecie, w którym potencjalny widz telewizji ma możliwość tworzenia i produkowania własnych treści, pozornie pełnej kontroli nad nimi, nie wydaje się dziwne, że telewizja zdaje się zapraszać publiczność do uspółtworzenia treści programowych, choć wysoce powierzchownie. Obiecuje przy tym pełną partycypację, niejednokrotnie tłumacząc, że to właśnie audytorium, publiczność, odbiorcy - a nawet lepiej: tzw. zwykli ludzie są jej celem i środkiem w produkcji medialnej. Co ciekawe, owej „zwykłości” telewizja już nie definiuje. Być może, mimo przypisywanej sobie plenipotencji do zarządzania codziennością i podkreślania nieodstępnych związków z rzeczywistością, tak naprawdę nie potrafi lub nie może wyzbyć się tradycyjnych (tutaj: utrwalonych) sposobów prowadzenia dyskursów i narracji?

Różnorakie koncepcje oddziaływania mediów uydają się dziś uniwersalne i wzajemnie kompatybilne. Niemal uszystkie zakładają sytuację modelową, która z konieczności musi pozostać uproszczona, lecz zawsze dotyczyć będzie możliwej interpretacji rzeczywistości ${ }^{3}$ - tej „przedtelewizyjnej”, istniejącej zanim telewizja zobrazuje i przekształci ją na swoje potrzeby. W prawie każdej teorii mediów, a szczególnie krytycznej, istotne jest podkreślanie absolutyzmu mediów masowych w reprezentowaniu i opisywaniu zdarzeń pochodzących z tzw. prawdziwego (pozatelewizyjnego) świata. Ważna staje się też kwestia sprawczości telewizji, czy też jej ingerencja w rzeczywistość, którą można badać z pomocą performatyki: interdyscyplinarnej dziedziny nauk humanistycznych i społecznych zajmującej się w zasadzie każdym działaniem o wymiarze kulturouym.

Przedmiot badań nazywam tutaj telewizją ponowoczesną, aby wyrazić różnorodność sposobów jej interweniowania w otaczający nas świat, definiowany w ostatnich kilku dekadach przez wielu badaczy jako płynny i dynamiczny. Interwencja w realność, którą mam na uwadze, w tej perspektywie interpretacyjnej ma konotacje konstruktywistyczne, to znaczy - najogólniej ujmując - zakładam, że telewizja współtworzy kształty rzeczywistości kulturowej zwanej ponowoczesną, istnieje na styku realności i medialności (u różnym stopniu), jednocześnie zaprzeczając telewizyjności i akcentując ją.

Oczywiście nie jestem u stanie przedstawić uszystkich nurtów, gatunków czy tendencji występujących obecnie w przekazach telewizyjnych, dlatego wybieram taką telewizję, która zdaje się najbardziej podkreślać „codzienność” i „rzeczywistość” - real

3 Zob. J.P. Hudzik, Teoria mediów w metarefleksji nad kultura [w:] Kulturowe kody technologii cyfrowych, red. P. Celiński, Wyższa Szkoła Przedsiębiorczości i Administracji, Lublin 2011, s. 78-80. 
$T V^{4}$. Nurt ten nie jest bezpośrednim gatunkouym przełożeniem tzw. reality media, którego podstawową cechą jest brak scenariusza (non-scripted) - oznacza to, że w real $T V$ następować będzie zrównanie autentyczności i fikcyjności przekazu, zarówno pod względem narracyjnym, jak i semantycznym. Ponadto treść takich programów wypełniać będzie tematyka możliwie najbardziej urażliwa społecznie. Tak określony przedmiot rozważań będę nazywał dalej zamiennie real $T V$, reality i telewizją rzeczywistości, lub niekiedy po prostu telewizją.

Podejmując tutaj wyzwanie, utrudnione przez stopień skomplikowania samego przedmiotu badań, jak również przyjętej metody badawczej: studiów performatycznych, stawiam pytania dotyczące funkcjonowania rzeczywistości w telewizji oraz realności tworzonej przez samą telewizję.

Na początku spróbuję osadzić telewizję u performatyce, odnosząc się do wybranych teorii performansu i zurotów kulturowych. Następnie podejmę próbę upisania w performatykę konstruktywistycznej wizji mediów masowych. Przejdę potem kolejno od poszukiwań performatywności w programie rozrywkouym do lokalizowania podobnych mechanizmów w programie informacyjnym.

\section{Telewizja jako performans}

Performatywność, którą zajmuje się performatyka, stanowi element ponowoczesności lub też przynajmniej jest z nią blisko zuiązana. Jedną z uyróżniających cech ponowoczesności jest to, że «zasadę performatyuną» stosuje się do wszystkich aspektów życia społecznego i artystycznego. Performans nie ogranicza się już do sceny, sztuki czy rytuału ${ }^{5}$.

Telewizyjne obrazy tłumaczone są często przez ich twórców jako wierne odwzorowanie realności, czyli otaczającego nas świata. Jednocześnie codzienność zapełniają ekrany telewizyjne ${ }^{6}$, niosące przekazy informacyjne, reklamowe, rozrywkowe - klasyfikacje typów i gatunków można by mnożyć, w zależności od przyjętego paradygmatu czy aspektu prowadzonych badań. W analizie telewizji rzeczywistości uyłania się zatem problem wielowątkowości, przez co jej interpretacja może nastręczać problemów. Niedookreśloność jawi się tutaj jako możliuy do przyjęcia desygnat ponowoczesności, u której łączyć i naprzemiennie pojawiać się będą zróżnicowane konteksty. Telewizja ponowoczesna wydaje się prawdopodobna do koncypowania w dyskursach

4 Zob. A. Ogonouska, Gatunki telewizyjne [w:] Stownik wiedzy o mediach, red. E. Chudziński, Wydawnictuo Szkolne PWN, Warszawa-Bielsko-Biała 2010, s. 318-320.

5 R. Schechner, Performatyka. Wstęp, tłum. T. Kubikouski, Ośrodek Badań Tuórczości Jerzego Grotouskiego i Poszukiwań Teatralno-Kulturowych, Wrocław 2006, s. 152.

${ }_{6} \mathrm{Na}$ ten temat zob. np. Z. Bauman, Społeczeństwo w stanie oblężenia, tłum. J. Margański, Wydawnictwo Sic!, Warszawa 2007, s. 184. 
humanistycznych doświadczonych tzw. zurotami: językowym ${ }^{7}$, piktorialnym ${ }^{8}$ (lub ikonicznym), postkolonialnym ${ }^{9}$ czy performatywnym ${ }^{10}$.

Wart uwagi jest dla mnie zwłaszcza ostatni z wymienionych. W swoim założeniu performatyka skupia się na przeprowadzaniu kompleksowej analizy rzeczywistego (rozumianego tutaj jako praktyczny) działania kulturowo-komunikacyjnego. Działanie owo można określić także jako „proces dialogicznego zaangażowania w swoją własną i związaną z innymi estetyczną komunikację przy użyciu środków performatywnych"11. Słowo „performatywny” (a tym samym związane z nim: performatyka, performans, performatyczny i inne) pochodzi od filozofa języka Johna L. Austina ${ }^{12}$, nie uymusza jednak przyjęcia podejścia opartego tylko na paradygmacie lingwistycznym. Telewizję ponowoczesną można więc określić jako performans. W tym miejscu skupię się na doprecyzowaniu znaczenia tego słowa. Szczególnie ciekawą definicję podaje Władysław Kopaliński:

Performance (ang.) - pojęcie określające rodzaj parateatralnych efemerycznych działań, tworzonych na żywo w obecności widzów, ale (w odróżnieniu od happeningu) nie dążących do ich uspółdziałania, stosowanych jako środek wyrazu artystycznego ${ }^{13}$.

Przytoczoną definicję potraktuję jako punkt wyjścia do dalszych rozważań. Performatyka będzie tutaj przeze mnie rozumiana jako rodzaj

gry, w której nieistotne jest przecież definiowanie pojęcia, choć i od niego, jak się okaże, nie sposób się uwolnić, ale odtworzenie dynamiki myśli, która być może ujaunia nową właściuość (zarówno myśl, jak i dynamika; zarówno «temat» jak i sama «technologia» jego formowania się) $)^{14}$.

7 Kompleksową analizę poszczególnych nurtów kulturowych przeprowadziła Doris Bachmann-Medick, wychodząc od zurotu językouego z jednoczesnym podkreśleniem znaczenia nowych teorii humanistycznych i społecznych, w szczególności drugiej połowy XX wieku. Zob. eadem: Cultural turns. Nowe kierunki w naukach o kulturze, tłum. K. Krzemieniowa, Oficyna Naukowa, Warszawa 2012, s. 42-56.

8 Ibidem, s. 427.

9 Ibidem, s. 214-216.

10 Ibidem, s. 119-162.

11 R. Pelias, Performance studies. The interpetation of aesthetic texts, Kendall/Hunt, Dubugue 1999, s. 15. Cyt. za: B.K. Alexander, Etnografia performatywna. Odgrywanie i pobudzanie kultury, tłum. Ł. Marciniak [w:] Metody badań jakościowych, t. 1, red. N.K. Denzin, Y.S. Lincoln, Wydawnictuo Naukowe PWN, Warszawa 2009, s. 581.

12 Zob. J.L. Austin, Wypowiedzi performatywne [w:] idem, Mówienie i poznawanie. Rozprawy i wykłady filozoficzne, tłum. B. Chwedeńczuk, Wydawnictwo Naukoue PWN, Warszawa 1993, s. 311.

13 W. Kopaliński, Stownik wydarzeń, pojęć i legend XX wieku, Wydawnictwo Naukowe PWN, Warszawa 1999, s. 309.

14 R. Maciąg, Performatywne skutki wypowiedzi publicznych. Droga do performatologii [w:] Performatywne wymiary kultury, red. K. Skowronek, K. Leszczyńska, Wydawnictwo Libron, Kraków 2012, s. 31. 
Sam performans warto dookreślić jeszcze jedną próbą zdefiniowania go u sposób, który wyraźniej uwidacznia sprawczość działań performatywnych, a także podejmuje kwestie jego realności:

Performans przede wszystkim jest działaniem spełnionym w świecie i stanowiącym prezentację zjawiska; działanie to odnosi się do reprezentacji (na przykład tekstu, scenariusza, scenopisu czy książki), używającej systemu semiotycznego (takiego jak język, schemat notacji, system matematyczny) ${ }^{15}$.

W przywołanej definicji, podobnie jak wcześniej u Kopalińskiego, zauważam istotne podkreślenie braku zaangażowania widzów w działanie. Jak więc telewizja rzeczywistości będzie podejmować relacje z realnością: widzami, publicznością, społeczeństwem, daną sferą kulturową? Istotne wydaje się w tym kontekście zdefiniowanie działań performatyunych telewizji jako spektaklu, spektaklu jako działania. W swojej poetyce będzie ono rzeczywiście pozbawione bezpośredniego, a przynajmniej zakładanego, upływu widzów na kulturową (medialną) materię przedstawienia. Komunikacja medialna jest oczywiście z założenia pośrednia, co dodatkowo ułatwia samolegitymizację działań nadawców w obliczu braku rzeczywistej konfrontacji z odbiorcą.

Wydaje się to bezpośrednio korelować z definiowaniem telewizji przez pojęcie mediów masouyych u ujęciu Niklasa Luhmanna. Wyróżniając funkcje mass mediów, wskazuje on na operacje i obserwacje, uyraźnie rozdzielając je od siebie jako niezależne elementy ${ }^{16}$. Niemiecki socjolog najpewniej mógłby nazwać tę relację systemem, a więc $\mathrm{w}$ pewnym stopniu zamkniętym układem.

Odnosząc się do zaproponowanej przez Kopalińskiego definicji performansu oraz kontynuując eksperymentalne zestawienie performansu z Luhmannowską teorią systemów, obserwacjami możemy nazwać także te operacje, które zachodzą na poziomie recepcji i percepcji - są społeczne i odrębne względem samego spektaklu. Same operacje natomiast pozostają faktycznym zachodzeniem uydarzeń - odnoszą się bezpośrednio do środków performatywnych zawartych w przedstawieniu. Oczywiście możliwe jest, co podkreśla Luhmann, sprzężenie zurotne obu tych zjawisk, jednak zachodzić ono będzie $w$ wewnętrznym systemie autopoesis ${ }^{17}$. Zatem możliwe jest dwojakie przyjęcie oddziaływań zewnętrznych czynników, takich jak samo oglądanie czy popularność programów, na uwarunkowania wewnętrzne (operacje), czyli działania performatyune. Po pierwsze, możliwa jest samokontrola twórcóu programu - przyglądanie się real TV samej sobie - jednak nie w lustrze, a od środka. Wykorzystywane do tego narzędzia, takie jak badania fokusowe czy wyniki oglądalności, są zestawiane

15 R.P. Crease, The Play of Nature: Experimentation as Performance, Indiana University, Bloomington 1993, s. 100. Cyt. za: J. McKenzie, Performuj albo... Od dyscypliny do performansu, tłum. T. Kubikouski, Towarzystwo Autorów i Wydawców Prac Naukouych Universitas, Kraków 2011, s. 164. Zostawiono wyróżnienia z tekstu oryginalnego.

16 Zob. N. Luhmann, Realność mediów masowych, tłum. J. Barbacka, Wydawnictwo Gajt, Wrocław 2009, s. 99-101.

17 Ibidem, s. 100. 
z uwarunkowaniami ekonomicznymi, poczuciem estetyki i know-how twórców. Filtrowanie zachodzi właśnie na poziomie metaprogramouym - wewnątrzsystemowym, jak zapewne nazwałby to Luhmann, samostanowiącym się i zarazem samolegitymizującym takie działanie.

Druga możliwość to uykorzystanie tylko obserwacji, czyli potencjalnie bezpośrednie oddanie audytorium decydowania o sposobie funkcjonowania systemu programowego telewizji. Choć brzmi to utopijnie, to w zestawieniu z potencjalną całkowitą autonomią telewizji traktowanej całościowo jako zjawisko jednorodne (w odszczepieniu od widowni), na pewno wypada korzystniej dla nadawców pod względem wizerunkowym. Być może stąd właśnie oparcie się na zbiorowym guście publiczności i dominujące, jeśli nie wypierające uszelkie inne, poza sentymentalnie komparatyunymi refleksjami, badania oglądalności?

Nasuwa się tu oczywista refleksja, że badania oglądalności i publiczności jako narzędzia socjologiczne są $\mathrm{u}$ zasadzie tożsame metodologicznie z badaniem preferencji wyborczych. Co ciekawe, wyniki sondaży pozostają możliwe do weryfikacji przez rzeczywistą partycypację społeczeństwa w demokratycznych wyborach i faktyczne dokonanie się mechanizmu elekcji - co widać potem w spersonalizowanych władzach politycznych. Zachodzi przeniesienie sposobu interpretacji z obszarów ekonomicznego i politycznego na możliwe do wyabstrahowania, a tym samym stosowania implicytnych metod, pole medioznaustua. Stosowanie tych narzędzi w odniesieniu do telewizji pozbawia możliwości sprawdzenia badań i uprzęga je tym samym w autologiczną koncepcję medióu masowych Luhmanna ${ }^{18}$, a pod uzględem samego stosowania jest działaniem performatywnym. Istotne jest tutaj rozróżnienie przymiotnikowania performatywny i performatyczny. Działanie jest performatyczne w obrębie teoretycznym, w praktyce zaś, sile funkcjonowania jest performatyune ${ }^{19}$. Tym samym performatywność, jako nieodstępna (pozornie) część przedstawienia, pozwala na sformułowanie metafory real TV jako spektaklu. Pytaniem do rozstrzygnięcia pozostaje, czy telewizja to spektakl rzeczywistości, czy rzeczywistość spektaklu?

\section{Performatywność medialnego spektaklu}

Problem ten odnoszę do rozważań Guya Deborda, który na początku swoich dociekań na temat społeczeństwa spektaklu stawia tezę o oddaleniu bezpośredniości przeżywania na rzecz przedstawienia ${ }^{20}$. Jest to $w$ istocie pytanie także o telewizję rzeczywistości, o sposób i stopień uykorzystania przez real TV faktycznej realności, jak róunież o róż-

18 Ibidem, s. 110.

19 Różnica, jaka poustaje z takiego podziału, przypomina naprzemienną relację między kulturouym a kulturalnym. Zob. więcej na ten temat: E. Bal, W. Świątkouska, Negocjacje terminologiczne [w:] Performans, performatywność, performer. Próby definicji i analizy krytyczne, red. E. Bal, W. Śuiątkouska, Wydawnictuo Uniwersytetu Jagiellońskiego, Kraków 2013, s. 15.

20 Zob. G. Debord, Społeczeństwo spektaklu oraz Rozważania o społeczeństwie spektaklu, tłum. M. Kuaterko, Państwouy Instytut Wydawniczy, Warszawa 2006, s. 33, teza 1. 
nicę między spektaklem a autentyzmem. Telewizja ponowoczesna nie tylko zagarnia elementy właściwe innym polom kulturowym (artystycznym, estetycznym) czy społecznym (politycznym, ekonomicznym), ale czyni je własnymi, przetwarzając je w nadrzędny dyskurs medialny, w którym

oderwane od wszystkich przejawów życia obrazy łączą się we uspólnym nurcie, tam wszakże nie da się już przywrócić jedności tego życia. Cząstkowe ujęcia rzeczywistości scalają się u nową ogólną jedność, tworząc wyodrębniony pseudoświat, przedmiot czystej kontemplacji ${ }^{21}$.

Parafrazując słowa francuskiego myśliciela: telewizja rzeczywistości, która operuje obrazami, dokonuje odwołania do realności za pomocą wybiórczych kadrów. Dopiero te, jako sposób opowiadania o świecie, tworzą osobny system społeczno-kulturowy. Rozbicie ,jedności życia”, o którym pisze Debord, a w konsekwencji uczynienia go przez telewizję teatralnym, próbuje się przekuwać między innymi w różnorodność dyskursywną telewizji. Moim celem nie jest jednak wykazanie, czym dokładnie zajmuje się telewizja rzeczywistości, lecz refleksja nad tym, jak tę rzeczywistość przekształca w spektakl, i odwrotnie ${ }^{22}$.

Spektaklistyczne ${ }^{23}$, by tak je nazwać, rozważania Deborda mogą być inspirujące dla interpretatorów telewizji i performatyków. Francuski filozof podkreśla, że

nie można abstrakcyjnie przeciustawiać spektaklu i rzeczywistej działalności społecznej: sama ta dwoistość podlega rozdwojeniu. Spektakl, który wyuraca rzeczywistość na opak, jest realnie wytwarzany ${ }^{24}$.

Wynika z tego, że telewizja rzeczywistości przez samo obrazowanie świata uytuarza również realność ${ }^{25}$. Jednocześnie zachodzi implikacja, że im większe u real TV odwołanie do rzeczywistości, tym bardziej przedstawienie staje się „prawdziwiej spektakularnym"26. Mamy więc do czynienia z zamkniętym obiegiem performatywnym.

Co ciekawe, stawiane w sposób odważny Debordouskie tezy są zbieżne z Luhmannowską koncepcją mediów masowych (głównie telewizji). Niemiecki konstruktywista

21 Ibidem, teza 2.

22 Konsekwencją tak stawianego problemu jest już oczywiście jakaś konkluzja, że przedmiotem prezentouania real TV jest szeroko rozumiana rzeczywistość: codzienność, niecodzienność, pouszedniość, odświętność, a także uszelkiego rodzaju zestawienia, odnoszące się do ludzkiego życia i kondycji ponowoczesnej. Przyjmując jednak metaforyczność określenia telewizji mianem spektaklu, zawężam problem do obszaru performatyki, podnosząc kwestię sprauczości przedstawienia. Na ten temat zob. np. E. Domańska, „Zwrot performatywny” we wspótczesnej humanistyce, „Teksty Drugie” 2007, nr 5, s. 60.

23 Zob. G. Debord, op. cit., s. 37, teza 14.

24 Ibidem, s. 35, teza 8.

25 Ibidem, s. 38, teza 18.

26 Ibidem, s. 112-113, teza 153. 
podkreśla samoreferencję jako podstawę funkcjonowania telewizji²7. Jednocześnie uskazuje, że niemożliwe u zasadzie jest oderwanie się mediów od społeczeństwa, zajmują się one bowiem tematami społecznymi i przez to są z nim ściśle związane ${ }^{28}$. Telewizja funkcjonuje jako system wewnętrznie zamknięty, który ingeruje w społeczeństwo, powodując zróżnicowanie $\mathrm{w}$ zasadzie jedynie $\mathrm{w}$ obszarze kognitywnym:

To ułaśnie u systemie mass medióu można rozpoznać konsekuencje, na które naraża się system, gdy poprzez operacjonalne zamknięcie wytwarza dyferencję systemu i środowiska, przez co wymaga, by wewnętrznie rozróżniać między samoreferencją i referencją obcą oraz by rozróżnienie to konkretyzować - w odniesieniu do każdorazowo zmieniających się stanów własnych ${ }^{29}$.

Sfera poznania uymaga rozróżnienia działań pojawiających się poza mediami ( $w$ „,realnej” realności: środowisku) oraz tymi w mediach (w realności medialnej: systemie). Referencja obca będzie więc znaczyła tyle, ile informacja rozumiana jako nośnik przetwarzanego znaczenia.

Luhmann dodatkowo dzieli mass media na trzy główne kategorie: informacje, reklamę i rozrywkę. Zaznacza, że wskutek rozwoju techniki, tworzenia pola komunikacyjnego oraz „udostępniania zaplecza wiedzy”, we uspomnianych obszarach programowych media „nie wydają się dążyć do wytworzenia jakiejś konsensualnej konstrukcji realności, a jeśli już, to bez powodzenia”30. Z rozważań niemieckiego socjologa można jednak wysnuć wniosek, że telewizja jako system funkcyjny oparty na swoistym kodowaniu (obrazowaniu) jest jednolitą strukturą w obrębie rzeczywistości ${ }^{31}$. Tworzy ją jako realną przez obrazowanie, czerpiąc jednocześnie ze środowiska zewnętrznego (każdego dowolnego), a następnie dopiero po przetworzeniu (uniwersalnym, jednościowym zobrazowaniu) różnicuje w strefach programowych - co można interpretować jako performatywne stawanie się telewizyjnego przedstawienia „bardziej przedstawieniowym", a zatem bliższym także realności.

\section{Realistyczne imaginacje telewizyjne}

Popularny w wielu dyskursach konflikt „materialne $v s$. niematerialne” może prowadzić do uwidocznienia problemów z określeniem estetyzacji uspółczesnej telewizji. W przypadku prezentowania czegokolwiek u telewizji rzeczywistości, czyli też wytwórstua i emisji każdego programu z tego nurtu, zachodzić będzie dialektyczne funkcjonowanie zjawisk właściwych ponowoczesności: komercjalizacji i rozrywkowości. Wydaje się, że oba te czynniki można odczytać wprost bez na przykład pogłębionej

27 Zob. N. Luhmann, op. cit., s. 15-19.

${ }^{28}$ Ibidem, s. 17.

${ }^{29}$ Ibidem, s. 18.

30 Ibidem, s. 73.

31 Ibidem, s. 75. 
analizy treści oraz bez refleksji performatycznej. Jednakże, przy wykorzystaniu tej ostatniej, najpewniej można ustalić cechy wspólne programów informacyjnych oraz rozrywkowych, w obrębie omawianego tutaj problemu, polegającego na płynności zamiarów postępowania przez twórców i producentów real $T V$ z rzeczywistością.

W celu zilustrowania przytoczonych konkluzji przykładem posłużę się w pierwszej kolejności programem Ugotowani telewizji TVN. Na stronie internetowej programu możemy przeczytać:

W każdym odcinku czwórka nieznajomych z jednego miasta spotyka się przy jednym stole. Każdy z nich przygotouruje kolację według ułasnego pomysłu, otwiera suój dom na nieznane i wystawia się na brutalne ostrze krytyki. Zuycięża ten, komu uda się oczarować gości najlepszą kolacją ${ }^{32}$.

Zacytowany opis prowadzi wprost do wniosku, że mamy do czynienia z programem typu reality show, a zatem spektaklem medialnym, który zawiera „elementy charakterystyczne dla teleturniejów, zarówno zręcznościowych (game shows), jak i tych dotyczących wiedzy (quiz shows), talk shows, telenoweli dokumentalnej oraz opery mydlanej"33. Gotowanie można z całą pewnością uznać za połączenie wiedzy i umiejętności. Pozostałe elementy przywołane z opisu programu nie funkcjonują jednak $w$ tych sferach.

„Otwarcie domu na nieznane” jest tutaj działaniem jedynie pozornym, ponieważ uczestnicy u zasadzie nie mają do czynienia z niczym niewiadomym, chyba że przyjąć tutaj spotkania z innymi jako obcymi, których

klasyfikacja rozłączna czyni semantycznie «niedookreślonymi», lub - przeciunie - obdarza naraz sensami, które logika klasyfikacji definiuje jako wzajem sprzeczne ${ }^{34}$.

Należy jednak podkreślić, że uczestnicy, godząc się na występ w odcinku, a których udział w nim wynika z dobrowolnego zgłoszenia się do programu, tworzą swoiste communitas jego użytkowników: nowej wersji widzów i uczestników medialnego show. Są więc jednocześnie strukturą i antystrukturą tego spektaklu, znajdują się liminalnie pomiędzy publicznością a jej reprezentacją. „Wystawienie się na brutalne ostrze krytyki" z kolei wydaje się wtórnym, replikowanym zabiegiem semantycznym, mającym za zadanie podniesienie atrakcyjności opisu programu, który jednocześnie służy za jego reklamę.

Spotkanie uczestników zachodzi zatem na poziomie pełnej akceptacji warunków stawianych przez twórców i producentów. Rzeczywistym pretekstem fragmentarycznego zejścia się ich losów nie jest otwarcie się na nieznane, lecz spotkanie

32 Strona internetowa programu, http://ugotowani.tvn.pl/o-programie,77113,n.html [dostęp: 7.04.2014].

33 A. Ogonouska, op. cit., s. 323.

34 Z. Bauman, Ponowoczesność jako źródło cierpień, Wydawnictuo Sic!, Warszawa 2013, s. 41. 
z całkowicie znanym, oswojonym światem, w warunkach pluralnego dostępu do realizacji swojego ego przez telewizję. Przez zabawowość oraz komercyjny charakter programu (zwycięzca otrzymuje nagrodę w wysokości pięciu tysięcy złotych, a podczas każdego etapu przygotowania potraw w rękach uczestników wdzięczą się lokowane produkty gastronomiczne), rywalizacja zostaje sprowadzona do poziomu spotkania towarzyskiego.

Zawodnicy dokonują wzajemnej oceny wrażenia (sic!), jakie wywołało u nich dane przyjęcie przygotowane przez poszczególnych uczestników za pomocą kart z punktacją. Ta refleksja odbywa się u samochodzie, który zapeune ma budzić skojarzenia z powrotem po imprezie taksówką do domu. Jakakolwiek ocena zdaje się funkcjonować tutaj w ramach samoodniesienia, czyli autopojetycznej pętli, która w tym przypadku pozbawia feedbacku widzów przed telewizorami na rzecz dychotomicznej reprezentacji społeczeństwa w postaci uczestników programu. Zachowania samych uczestników są ponadto komentowane u lekki sposób przez lektora, który również wypowiada zdania oceniające, nieraz umniejszając znaczenie słów i działań konkursowiczów, tym samym „odzierając” ich ze sztuczności. Jest to zabieg podważający realność tego reality, ponieważ głos lektora jest głosem twórców i producentów, zatem następuje tu korespondencja między rzeczywistością u momencie obrazowania (nagrywanym spektaklem) a rzeczywistością emitowaną (zmontowaną).

Ugotowani są ucieleśnieniem kultury cuisine $e^{35}$ wprzęgniętej w samonapędzający się komercyjny charakter mediów. Gotowanie na ekranie jest tu jednocześnie hiperrealne - prezentowanym potrawom nadawane są udziunione nazwy, jak „ogon bobra” czy „szczęśliue pielmieni”, a przepisy są dostępne na stronie internetowej programu, skąd mają szansę przejścia i „stania się": od realności domu, gdzie zapewne na co dzień poustają, przez rzeczywistość telewizyjną (która nadaje im doniosłości, mimo że są tylko powielane), a następnie do rzeczywistości odbiorców - kognitywnej, lecz wysoce spekulatywnej.

Istotną kwestią jest także realność scenograficznego planu tego programu. Spotkania odbywają się w domach uczestników, gdzie widać ślady bytności także ich rodzin: zabawki dzieci, zdjęcia, przedmioty codziennego użytku partnerów. Podczas realizacji programu rodzina zostaje jednak wyeksmitowana. Uczestnik ukazany jest jako singiel, na potrzeby scenariusza przyjmuje zatem fałszywą tożsamość. Równie nierealistyczne wydają się, również upisane w konwencję formatu, obowiązkowe niespodzianki, jakie każdy uczestnik musi przygotować. Przykładowo w jednym z odcinków ${ }^{36}$ zawodnicy symulowali lot balonem bez balonu, stojąc jedynie w koszu ustawionym u ogrodzie jednego z konkursowiczów, z palnikami do podgrzewania powietrza w rękach. Wydaje się to wyjątkową egzemplifikacją nierealności real TV oraz jej performatywności, gdzie udawanie (spektakl) staje się ważniejsze od rzeczywistego stanu rzeczy.

35 Zob. M. Bogunia-Borouska, Fenomen telewizji. Interpretacje socjologiczne i kulturowe, Wydawnictwo Uniwersytetu Jagiellońskiego, Kraków 2012, s. 251.

36 Ugotowani, emisja w TVN w niedzielę 6 kwietnia 2014 roku o godzinie 18:00. 
Być może wartą docenienia cechą Ugotowanych jest różnorodność uczestników pod uzględem pochodzenia i statusu materialnego. W przywołanym odcinku uystępowali obcokrajoucy mieszkający w Polsce: Chinka, Rosjanka, Holender i Kanadyjczyk. Przygotowali oni, zgodnie z możliuym do przewidzenia przebiegiem scenariuszouym, potrawy związane z krajem swojego pochodzenia. Można zastanawiać się nad walorem poznawczym takiego doboru uczestników. Program nie pełni funkcji edukacyjnej, ani nie jest $\mathrm{w}$ istocie reprezentacją obszaru kulturowo-tożsamościowego ${ }^{37}$, choć może się takim zdawać. Zróżnicowanie zawodników jest tu jedynie środkiem do celu, jakim jest wyprodukowanie odcinka. Równie dobrze mogłyby u nim brać udział zupełnie inne osoby, reprezentanci lokalnych społeczności lub jeszcze innych kultur. Widz został w tym przypadku zaznajomiony u sposób bardzo powierzchowny z daniami poszczególnych krajów oraz w jeszcze bardziej ograniczonym zakresie z elementami ich kultury. Jest to jednak efekt uboczny, natomiast rzeczywistą intencją zdaje się wpisanie potencjalnie jak największej liczby ludzi w konwencję formatu, co ma zapewnić ciągłość produkcji na podstawie atrakcyjności, rozumianej tu jedynie jako powierzchowne zróżnicowanie bohaterów.

W Ugotowanych mamy ponadto do czynienia z ludycznością działań, które u real $T V$ opierają się na uwydatnieniu stosunków międzyludzkich oraz podnoszeniu zwykłych czynności (w tym przypadku gotowania) do rangi niezwykłych ${ }^{38}$. Nie ulega też wątpliwości, że program ten opiera się na trzech działaniach performatywnych: spotkaniu ludzi (w rytualnej formie, podlegającej dodatkowo kryterium samooceny grupy), przygotowaniu potraw (działaniu sprawczym, wytwórczym, poddawanym ocenie estetycznej) oraz zorganizowaniu niespodzianki (na wzór happeningu, jednak bardziej performansu z uwagi na spektakularność programu). Element uspółzawodnictua jest tu głęboko ukrytym performatywem, który „zaciera definicje ludycznej i realnej”39 funkcji tego programu. Cały program jest mieszanką performansów ${ }^{40}$ : codziennego, czasu wolnego, świątecznego, organizacyjnego, technologicznego, artystycznego czy nawet politycznego - gdzie ten ostatni być może realizowany jest, analizując tym razem z perspektywy teorii krytycznej, w ramach dyskursu klasowo-ideologicznego, w którym eksponowane są „sposoby partycypacji w życiu codziennym lepiej sytuowanych" ${ }^{\text {"11 }}$ a zatem następuje dyskryminacja ubogiej części społeczeństwa i obszarów poza dużymi miastami.

37 Por. M. Bogunia-Borouska, op. cit., s. 266.

38 Zob. A. Duda, Performans na żywo jako medium i obiekt mediatyzacji, Wydaunictwo Naukowe Uniwersytetu Mikołaja Kopernika, Toruń 2011, s. 312.

39 Ibidem, s. 311.

40 Zob. klasyfikacje performansów i przynależne im czynności, J. Wachouski, Performans, słowo/obraz/terytoria, Gdańsk 2011, s. 50-51.

41 M. Bogunia-Borouska, op. cit., s. 262. 


\section{Informacja performowana}

Dokonam teraz zestawienia poczynionych rozważań z przykładem pochodzącym z nurtu informacyjnego. Choć takie porównanie może wydawać się nieupraunione, z uwagi na różnice genologiczne i typologiczne komparowanych programów, postaram się uykazać niemal identyczne procesy performatywne, które konstruują ostatecznie rzeczywistość w programie informacyjnym. Wewnętrzny konflikt realności telewizji przybierze tu inne oznaki z uwagi ułaśnie na różnice między prezentacją funkcji informacyjnej a prezentacją funkcji rozrywkowej, jednak w ramach tego samego klucza konsumpcyjno-rozrywkowego oraz podobnych sposobów uniwersalności ${ }^{42}$, w transformacji działań. Obszar informacji i obszar rozrywki

używa kodu informacja-nieinformacja, każdorazowo w bardzo różnych zastosowaniach; te rozróżniają się na podstawie kryteriów, które leżą u podstaw uyboru informacji. [...] Nie powinno się przy tym wykluczać ich krzyżowania się, a przede wszystkim w każdym z tych obszaróu można stwierdzić zurotne usieciowienie z tym, co uważane jest za moralne przekonania czy typowe preferencje publiczności ${ }^{43}$.

Przedmiotem porównania uczynię tu krótki serwis informacyjny w kanale TVN24 $4^{44}$. Pierwsze trzy informacje dotyczyły nieszczęśliwych wypadków: pierwszy kraksy na autostradzie A4 pod Katowicami z ofiarą śmiertelną, drugi postrzału pod Kamieniem Pomorskim z jedną ofiarą śmiertelną, trzeci pożaru budynku, w którym zginęly dwie osoby. Mam świadomość drastyczności przywoływanych wydarzeń, a także szokującego zestawienia programu rozrywkowego z takimi informacjami. Zależy mi jednak na jak największej obrazowości porównania, a zarazem przedstawienia performansu u możliwie najszerszym kontekście.

Co może łączyć te dwa programy? Przede uszystkim zaangażowanie rzeczywistych osób w treść audycji. W pierwszym przypadku jest ono oczywiście dobrowolne, w drugim zachodzi całkowicie poza wolą, ponieważ mamy do czynienia ze zmarłymi. $\mathrm{W}$ pierwszym osoby były przedstawione imieniem i nazwiskiem, w drugim pozostały anonimowe. Jednakże w obu mamy do czynienia z intencją twórców i producentów programów u zaangażowanie w scenariusz rzeczywistych ludzi. Niemożliwy jednak staje się $\mathrm{w}$ real $T V$ rzeczywisty obraz śmierci, choćby dlatego, że ta „stała się tak abstrakcyjna, że nie pociąga już za sobą pytania o sens" ${ }^{\text {”t }}$. Innym uwarunkowaniem braku realnego zobrazowania tych uydarzeń jest nieobecność kamer podczas ich zdarzania się. Pozbawiło to jednocześnie autoróu informacji (pracouników telewizji, nie sprawców wydarzenia) możliwości relacji, czyli podstawowego zadania telewizji informacyjnej. Jednocześnie ów „brak sensu” w pytaniu o informowanie o takich dra-

42 Zob. N. Luhmann, op. cit., s. 32.

43 Ibidem.

44 Serwis informacyjny, emisja w TVN24 w niedzielę 30 marca 2014 roku o godzinie 15:30.

45 H. Belting, Antropologia obrazu. Szkice do nauki o obrazie, thum. M. Bryl, Towarzystwo Autorów i Wydawcóu Prac Naukouych Universitas, Kraków 2012, s. 171. 
stycznych zdarzeniach jest tożsame z pytaniem o sens wcześniej omawianego programu rozrywkowego, a dokładnie o intencję towarzyszącą jego poustawaniu.

Przyjmę tutaj, że w Ugotowanych imaginowana intencja to po prostu wyprodukowanie programu, sprzedanie go i jednocześnie spowodowanie pewnego zaciekawienia u widza - będącego efektem „reprodukcji i informacji, kontynuowania zausze wcześniej dopasowanej «autopoesis» i kognitywnej gotowości irytacyjnej” ${ }^{46}$.

W serwisie informacyjnym TVN24 zafunkcjonował ten sam mechanizm, który można wytłumaczyć jako konieczność wyemitowania programu oraz powodowanie potencjalnego wzrostu oglądalności za pomocą prezentowania zdarzeń powodujących zaciekawienie. Odniesienie do oglądalności jest znowu zuróceniem się do ilości ${ }^{47}$, czyli mas, które jednak nie przemówią tutaj niczym innym, jak interpretacją działań twórców i autorów programu.

Jakieś urażenie pozostaje jednak po zobaczeniu wyemitowanych po sobie trzech informacji o śmierci. Można zastanawiać się, jaka była intencja wydawcy tego serwisu. Zapeune mógł on uwierzyć, że spełni funkcję informującą o wszystkim ważnym, a więc także o wypadkach, które mają być przestrogą dla widzóu (choć zastanawiam się, co w polskim społeczeństwie, w zasadzie pozbawionym dostępu do broni, pomogłoby uniknąć śmierci w wyniku postrzału). Na pewno jednak jego intencją było podtrzymanie kontaktu z widzem, wzbudzenie jego zainteresowania, uznanie, że u niedzielne popołudnie są to informacje ważne i stwarzające realność ${ }^{48}$. Były zaproszeniem do uspólnego przeżycia, uczestnictwa u communitas, które zostaje tu przemienione w całą społeczność potencjalnych widzów. A jednak „przeżyć zdarzenie w obrazie nie oznacza zyskać obraz tego zdarzenia ani nadać mu suobodę tego, co wyobrażone"49. Oznacza to, że przedstawienie trzech okoliczności śmierci u real TV pozostało powierzchowne i nie wniosło niczego do obszaru poznawczego odbiorcy. Założona (bezwiednie zapewne) liminalność, imaginacja płynnego „przejścia” przez wrażenie uspółczucia czy żalu, została tu uyeliminowana. Wydarzenia te, mimo swojej tragicznej wymouy, stały się jedynie częścią programu, który w dodatku można by sobie spokojnie wyobrazić bez nich. Pozostały czystym performansem.

Warto podkreślić, że magazyny informacyjne są róunież reprezentantami telewizji rzeczywistości z uwagi na „uszechobecność, relacjonowanie na żywo, uzależnienie od

46 N. Luhmann, op. cit., s. 101.

47 Ibidem, s. 37.

${ }^{48} \mathrm{~W}$ tym miejscu rozszyfrowywanie intencji zdaje się upodabniać do opozycyjnego dekodowania u teorii Stuarta Halla. Jednakże analiza performatyczna, mająca cechy hermeneutycznej, a zatem łącząc analizę treści, zawartości i dyskursu na poziomie działania medium, wydaje się tłumaczyć to podobieństwo w ramach założenia preferowanego odczytania tekstu medialnego. Zob. S. Hall, Kodowanie i dekodowanie, tłum. W. Lipnik, I. Siwiński, „Przekazy i Opinie” 1987, nr 1-2. Por. komentarz do tego, np. D. McQuail, Teoria komunikowania masowego, tłum. M. Bucholc, A. Szulżycka, Wydawnictwo Naukowe PWN, Warszawa 2008, s. 88-90.

${ }^{49}$ M. Blanchot, Trupie podobieństwo, tłum. A. Leśniak [w:] Antropologia kultury wizualnej. Zagadnienia i wybór tekstów, red. I. Kurz, P. Kuiatkouska, Ł. Zaremba, Wydawnictwa Uniwersytetu Warszauskiego, Warszawa 2012, s. 89. 
uydarzeń" ${ }^{50}$. Ich realność powoduje możliwość traktowania ich w kategorii performansu. Analizowany przypadek jest znowu kompilacją performansów, podobnie jak Ugotowani. Nie występuje tu jedynie performans polityczny, który można przenieść do społecznego i wówczas kwalifikowany byłby jako tzw. socjonews ${ }^{51}$, w obszarze eksploracji tematów związanych z lękami życia codziennego. Konieczne jest tu jednak rozszerzenie tej kategorii o kontekst samego nadania i płynnej intencji twórców i producentów real $T V$. Może to stanowić także unieważnianie realnej rzeczywistości lub świadczyć o obecności uniwersalnego, performatywnego mechanizmu transformacji działań. Nawet wydarzenia tragiczne, także przez ich kumulowanie, zostają przekute $w$ komercyjny produkt oraz służą, niestety, rozrywce $-\mathrm{w}$ ramach podtrzymywania teleobecności. Telewizja jest tutaj performatyuna, ponieważ „pływa” między obrazowaniem dowolnej realności a fabrykowaniem spektaklu, rozumianego jako produkt i zarazem walor sam $w$ sobie: jako desygnat autopojetycznego charakteru opisywanego medium.

\section{Podsumowanie}

Przedmiotem rozważań była tutaj szeroko rozumiana telewizja rzeczywistości - real $T V$, stanowiąca zaledwie skromny wycinek z bogactwa telewizyjnych przekazów. Próbując nazwać taką telewizję ponowoczesną, wydaje się, że w gruncie rzeczy to, co dziś określane jest płynnością, zmianą, przewartościowaniem, u telewizji ogółem istnieje od co najmniej kilkudziesięciu lat. Wtedy też zaczęły się konstytuować wielkie teorie ponowoczesności - by przywołać tu choćby Jeana-Françoisa Lyotarda, który Kondycje ponowoczesna... napisał w latach 70. ubiegłego wieku ${ }^{52}$. Telewizja ponowoczesna nie może być więc zjawiskiem całkiem nowym, a jej performans, czyli orientacja ku codzienności, pouszedniości i rzeczywistości, ma wieloletnie tradycje i głębokie ukorzenienie.

Niemniej jednak, próbując odpowiedzieć na formułowane tutaj pytania badawcze, muszę stuierdzić, że tendencje uspółczesnej telewizji do „urealniania” swoich programów wydają się dominować zarówno jej estetykę, jak i determinują dokonywane przez nią wybory narracyjne oraz reprezentacje ideologiczne. Performatywność, którą usiłowałem odnaleźć w programach nurtu reality, utrwala hegemoniczną, autorytarną rangę telewizji pośród innych mediów oraz sprawia, że twórcy, producenci i prawdopodobnie niektórzy odbiorcy czują się uyróżnieni obcowaniem z tak rozumianym medium, zdaje im się bowiem dotykać realności u najczystszej postaci.

Niniejsze rozważania traktuję jako próbę zainicjowania tak prowadzonego dyskursu o telewizji. Mam nadzieję, że proponowana przeze mnie siatka pojęciowa

50 A. Ogonouska, op. cit., s. 321.

51 Por. M. Bogunia-Borouska, op. cit., s. 209.

52 J.-F. Lyotard, Kondycja ponowoczesna: raport o stanie wiedzy, tłum. M. Kowalska, J. Migasiński, Aletheia, Warszawa 1997. 
i metodologia badań wpisują się w szeroko pojęty paradygmat medioznawczy. Nie zawsze uszak musi być on realizowany z laboratoryjną dokładnością i z uykorzystaniem tych samych, sprawdzonych środków. Liczę, że performatyka, przez którą próbowałem znaleźć potwierdzenie nierzadko własnych intuicji, znalazła naukowe uzasadnienie.

\section{Bibliografia}

Alexander B.K., Etnografia performatywna. Odgrywanie i pobudzanie kultury, tłum. Ł. Marciniak [w:] Metody badań jakościowych, t. 1, red. N.K. Denzin, Y.S. Lincoln, Wydawnictuo Naukoue PWN, Warszawa 2009.

Austin J.L., Wypowiedzi performatywne [w:] idem, Mówienie i poznawanie. Rozprawy i wykłady filozoficzne, tłum. B. Chwedeńczuk, Wydawnictwo Naukowe PWN, Warszawa 1993.

Bachmann-Medick D., Cultural turns. Nowe kierunki w naukach o kulturze, tłum. K. Krzemieniowa, Oficyna Naukowa, Warszawa 2012.

Bal E., Świątkouska W., Negocjacje terminologiczne [w:] Performans, performatywność, performer. Próby definicji i analizy krytyczne, red. E. Bal, W. Świątkouska, Wydaunictuo Uniwersytetu Jagiellońskiego, Kraków 2013.

Bauman Z., Ponowoczesność jako źródło cierpień, Wydaunictwo Sic!, Warszawa 2013.

Bauman Z., Społeczeństwo w stanie oblężenia, tłum. J. Margański, Wydaunictwo Sic!, Warszawa 2007.

Belting H., Antropologia obrazu. Szkice do nauki o obrazie, tłum. M. Bryl, Towarzystwo Autorów i Wydawców Prac Naukowych Universitas, Kraków 2012.

Blanchot M., Trupie podobieństwo, tłum. A. Leśniak [w:] Antropologia kultury wizualnej, Zagadnienia i wybór tekstów, red. I. Kurz, P. Kuiatkouska, Ł. Zaremba, Wydawnictua Uniwersytetu Warszawskiego, Warszawa 2012.

Bogunia-Borouska M., Fenomen telewizji. Interpretacje socjologiczne i kulturowe, Wydawnictuo Uniwersytetu Jagiellońskiego, Kraków 2012.

Crease R.P., The Play of Nature: Experimentation as Performance, Indiana University, Bloomington 1993.

Debord G., Społeczeństwo spektaklu oraz Rozważania o społeczeństwie spektaklu, tłum. M. Kuaterko, Państuouy Instytut Wydawniczy, Warszawa 2006.

Domańska E., „Zwrot performatywny” we wspótczesnej humanistyce, „Teksty Drugie” 2007, nr 5.

Duda A., Performans na żywo jako medium i obiekt mediatyzacji, Wydaunictwo Naukoue Uniwersytetu Mikołaja Kopernika, Toruń 2011.

Hall S., Kodowanie i dekodowanie, tłum. W. Lipnik, I. Siwiński, „Przekazy i Opinie” 1987, nr $1-2$.

Hudzik J.P., Teoria mediów w metarefleksji nad kultura [w:] Kulturowe kody technologii cyfrowych, red. P. Celiński, Wyższa Szkoła Przedsiębiorczości i Administracji, Lublin 2011.

http://ugotowani.tvn.pl/o-programie,77113,n.html [dostęp: 7.04.2014].

Kopaliński W., Stownik wydarzeń, pojęć i legend XX wieku, Wydawnictwo Naukowe PWN, Warszawa 1999. 
Luhmann N., Realność mediów masowych, tłum. J. Barbacka, Wydawnictuo Gajt, Wrocłau 2009.

Lyotard J.-F., Kondycja ponowoczesna: raport o stanie wiedzy, tłum. M. Kowalska, J. Migasiński, Aletheia, Warszawa 1997.

Maciąg R., Performatywne skutki wypowiedzi publicznych. Droga do performatologii [w:] Performatywne wymiary kultury, red. K. Skowronek, K. Leszczyńska, Wydawnictwo Libron, Kraków 2012.

McKenzie J., Performuj albo... Od dyscypliny do performansu, tłum. T. Kubikouski, Towarzystuo Autorów i Wydawców Prac Naukouych Universitas, Kraków 2011.

McQuail D., Teoria komunikowania masowego, tłum. M. Bucholc, A. Szulżycka, Wydawnictwo Naukowe PWN, Warszawa 2008.

Miller T., Turn Off TV Studies!, „Cinema Journal” 2005, vol. 45, nr 1.

Ogonouska A., Gatunki telewizyjne [w:] Stownik wiedzy o mediach, red. E. Chudziński, Wydawnictwo Szkolne PWN, Warszawa-Bielsko-Biała 2010.

Pelias R., Performance studies. The interpetation of aesthetic texts, Kendall/Hunt, Dubugue 1999.

Sanakiewicz M., Telewizja ponowoczesna. Logiki i imaginacje medialne, Novae Res, Gdynia 2016.

Schechner R., Performatyka. Wstęp, Ośrodek Badań Tuórczości Jerzego Grotouskiego i Poszukiwań Teatralno-Kulturouych, Wrocław 2006.

Wachouski J., Performans, słowo/obraz/terytoria, Gdańsk 2011. 